\title{
Osteoid Osteoma as a Cause of Hip Pain
}

\author{
Capt M P Grevitt* \\ $M B, F R C S$, RAMC \\ Dept of Surgery, British Military Hospital, Rinteln, BFPO 29
}

SUMMARY: A case of osteoid osteoma presenting with hip pain is described; the diagnosis and treatment of the tumour $\overrightarrow{\vec{ल}}$ is discussed.

\section{Introduction}

Osteoid osteoma is a relatively common benign tumour of bone first described by Jaffe in $1935^{1}$.

The tumour is usually a small mass in the cortex that produces skeletal pain. Adolescent and young adult males are most frequently affected. This report is of a case presenting with hip pain.

\section{Case Report}

A 33 year old man, who was a keen marathon runner, presented to his general practitioner in May 1987 with left groin pain of increasing severity.

This was initially exacerbated by running and relieved by rest. A muscle sprain was diagnosed but a course of physiotherapy proved of little benefit; ibuprofen $400 \mathrm{mg}$ tds only partially relieved the pain. When first seen in outpatients in September 1987 the pain had begun to interfere with the patient's sleep. On examination there was slight wasting of the quadriceps femoris muscles, tenderness over the medial part of the femoral triangle and pain with limitation of movement with flexion and internal rotation of that hip.

All haematological investigations were normal.

Radiographs revealed thickening of the cortical bone of the left femoral neck with a central radiolucent area at the level of the lesser trochanter (Fig 1).

A therapeutic trial of aspirin produced marked relief of symptoms within 20 minutes, lasting for over four hours.

A technetium - $99 m$ methylene diphosphonate radionuclide bone scan revealed a focus of increased activity in the region of the left lesser trochanter (Fig 2). A diagnosis of osteoid osteoma was made.

The neck of the left femur was explored via a SmithPeterson approach. The position of the central radiolucent area in the thickened cortex was identified by using marker K-wires and radiographs.

It was found to be on the medial surface of the calcar femorale: the tan coloured soft tissue curetted out with ease. The specimen was sent for histological examination. This revealed a proliferation of osteoblasts with uniform nuclei mixed with fragments of partially calcified osteoid, confirming a diagnosis of osteoid osteoma,

In the immediate postoperative period the patient stated that the original pain had disappeared. On follow up he has had no recurrence of symptoms and regained full range of pain free hip movements.

"Now Cambridge Military Hospital, Aldershot, Hants GU11 2AN.

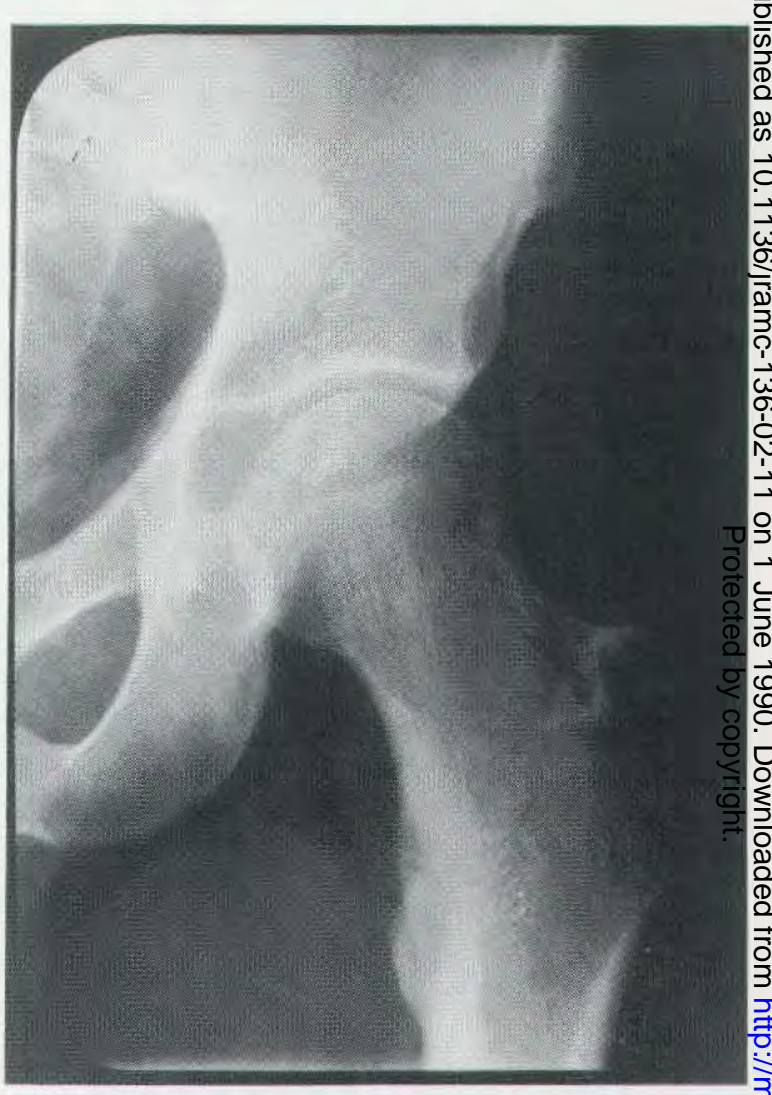

Fig 1. Radiograph of the left hip showing radiolucent cortical area of medial femoral neck.

\section{Discussion}

Osteoid osteoma is a neoplasm of bone that comprises approximately 20 per cent of benign bone tumours. It is found four times more commonly in males than females, $\frac{0}{3}$ with most $(80 \%)$ presenting within the first three decades of life. At least half of all osteoid osteomas? occur in the femur and tibia; over a third occur in the region of the hip ${ }^{2}$. This case illustrates some of the diagnostic problems associated with osteoid osteoma.

The most important presenting complaint is pain of increasing severity. The duration of symptoms may vary from weeks to years. The pain may have a nocturnale exacerbation and salicylates therapy often relieves it 
Referred pain to adjacent joints or those tumours near a joint may simulate an arthropathy.

The most striking physical finding is that of tenderness, which may be exquisite and usually accurately localised by the patient. Periarticular lesions may cause painful limitation of joint movement. Involvement of the lower limb usually produces a limp and muscle atrophy ${ }^{3}$, which when considered with the character of the pain may even suggest a neurological disorder. Furthermore, a limp, limitation of joint movement and response to salicylates can occur in any non-specific inflammatory arthritis. Delay in diagnosis is not uncommon. Radiographs of a mature lesion reveal a characteristic picture. The active nidus is usually a small round area of reduced density. Surrounding this nidus a thick area of sclerotic bone is frequently present. If the lesion is in a juxtacortical position the regional hypertrophy, especially along the periosteal surface, is much greater. In some instances the typical clinical symptoms precede the onset of recognisable radiological changes ${ }^{5}$. With early lesions an abnormality may only be found on radionuclide bone scan. The typical osteoid osteoma shows an intense focal increase in tracer uptake. Periarticular tumours may show a diffuse pattern of increased uptake in the region of the affected joint but not specifically in the nidus. Repeat scanning after 6 to 12 months may identify the nidus in these cases $^{6}$.

The treatment is complete surgical removal of the nidus. Traditionally this comprises en bloc excision of it with some surrounding bone. Lesser procedures were claimed to be associated with an increased incidence of

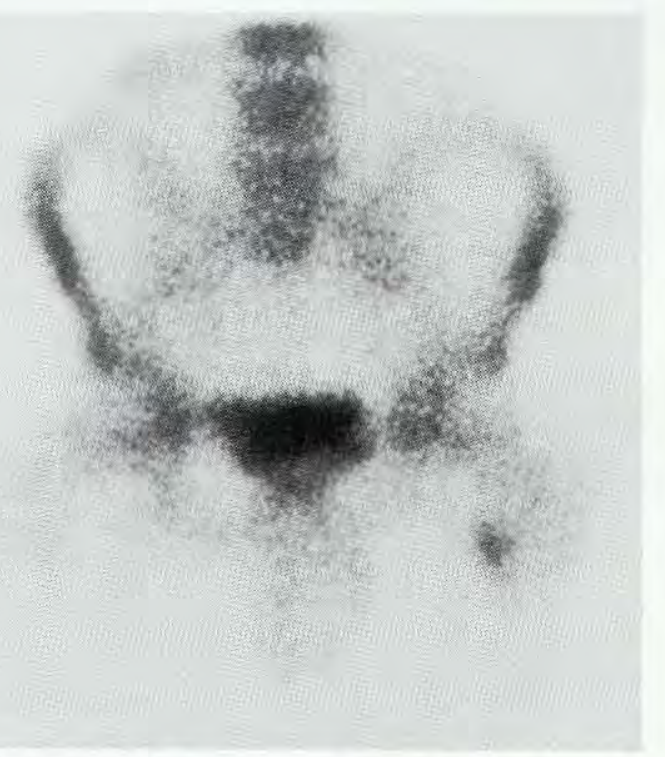

Fig 2. Radionuclide bone scan demonstrating area of increased focal activity in left lesser trochanter. recurrent symptoms 7 . However, if bone resection is extensive pathological fracture can occur, requiring internal fixation or prolonged immobilization. An alternative technique of shaving the reactive bone till the nidus is encountered followed by curettage of the exposed nidus, appears not to be associated with increased incidence of recurrence ${ }^{8}$. The proximity of the tumour to the calcar femorale in this patient militated against en bloc resection and the latter approach was adopted. This decision has been vindicated by the abolition of the previous pain in the immediate postoperative period. The patient remains pain free on subsequent follow-up.

\section{Conclusion}

A diagnosis of osteoid osteoma should be considered in cases of hip pain of obscure origin. Diagnosis may be delayed unless the tumour is included in a differential diagnosis, especially in a patient under 30 years of age. Plain radiography and radionuclide bone scans are useful investigations.

\section{Acknowledgements}

I wish to thank Major A D L Green for permission to report his patient, Lt Colonel R F MacDonald for advice in the preparation of the manuscript and Mrs F Sheppard for her secretarial assistance.

\section{REFERENCES}

1. JAFFE H L. Osteoid Osteoma: a benign osteoblastic tumour composed of osteoid and atypical bone. Arch Surg 1935 ;0 31: 709-728.

2. DAHLIN D C. Bone Tumours. General aspects and data on 6,221 cases. 3rd Edn Springfield Illinois. Charles C Thomas. 1978; 75-85.

3. Sherman M S. Osteoid Osteoma: review of the literature and report of thirty cases. J Bone Joint Surg 1947; 29: 918930.

4. Kumar S J. Osteoid Osteoma of the Proximal Femur: New techniques in Diagnosis and Treatment. J Paediatr Orthop $1984 ; 4: 669-672$.

5. Kattapuram S V. Osteoid Osteoma: An unusual cause of articular pain. Radiology 1983; 147: 383-387.

6. JAMESON Evans J $\mathrm{C}$ et al. The value of bone scanning in the early diagnosis of Osteoid Osteoma. I Bone Joint Surg 1977; 59B: 128.

7. PonsetI. Osteoid Osteoma. J Bone Joint Surg 1947; 29 : 767-776.

8. Carnesale P G. Benign Turmours of bone. In: Crenshaw AH ed. Campbells Operative Orthopaedics. 7th edn. St Louis Missouri. C V Mosby 1987; 756. 